\title{
Impact of Economic Policy Uncertainty on Chinese Carbon Price
}

\author{
Chen Ling-Ling, Wang Wen-Jun* \\ School of Economics, Hefei University of Technology, Hefei, China \\ Email address: \\ 1010040746@qq.com (Chen Ling-Ling), wenjunwang16@163.com (Wang Wen-Jun) \\ ${ }^{*}$ Corresponding author
}

\section{To cite this article:}

Chen Ling-Ling, Wang Wen-Jun. Impact of Economic Policy Uncertainty on Chinese Carbon Price. International Journal of Economy, Energy and Environment. Vol. 4, No. 1, 2019, pp. 18-23. doi: 10.11648/j.ijeee.20190401.13

Received: January 23, 2019; Accepted: March 12, 2019; Published: March 30, 2019

\begin{abstract}
There are direct as well as indirect linkages between economic policy uncertainty and carbon market through the channels of market fundamentals. This paper theoretically analyzes the linkages between economic policy uncertainty and carbon price and empirically examines the impact of Chinese economic policy uncertainty on Hubei carbon prices. A two-regime Markov-Switching process is introduced into the VAR model to examine the impact of economic policy uncertainty during different regimes of the carbon market. The empirical results show that the two-regime Markov-Switching model applies well in modelling the return series from Hubei carbon market during April 2014 to December 2017. Under the two different regimes, although the impacts from economic policy uncertainty are both significantly positive, the magnitude of the impacts differs. The impact of Chinese economic policy uncertainty on Hubei carbon price is larger during the low volatility period on carbon market than that during the high volatility period on carbon market.
\end{abstract}

Keywords: Economic Policy Uncertainty, Carbon Market, Markov Regime Switching, Impulse Response Function

\section{Introduction}

Economic policy uncertainty (referred as EPU hereinafter), which is defined as uncertainty regarding fiscal, regulatory, or monetary policy [1], has influences on a number of financial and economic fundamentals. Recent studies have examined the effect of EPU on inflation and output [2], unemployment [3], economic development [4], monetary policy effects [5], real housing returns [6], commodity markets [7], exchange rate expectations [8], corporate governance [9], corporate investment [10], stock and bond market correlation [11], co-movement of stock markets [12], stock market volatility [13], financial stress [14], and sources of global stock market risk [15]. The key message from these studies is that EPU has a significant impact on both economic fundamentals as well as financial markets, since high uncertainty in the economy can influence the decision-making process of firms, consumers as well as investors.

Factors affecting carbon prices have been extensively covered in existing literature, which have stated that energy prices [16], macroeconomics [17], production technologies [18], natural disasters [19], market environment [20] and many other variables impact carbon price. Among them, policy factors are considered to be one of the important factors affecting the carbon market [21].

The generation and operation of the carbon market are primarily dependent on the government's economic policies. Especially, for the cap-and-trade system implemented in the pilot markets in China, the carbon allowances for the market are determined by the policy directly. Apart from this direct linkage between economic policy uncertainty and carbon prices on the supply side, uncertainty induced by economic policy has various indirect means to impact the demand side of the carbon market [22-24]. In the short term, EPU impacts carbon price due to its influence on output and energy prices, which lead to the changes in carbon permit demands $[25,26]$, In the long run, EPU impacts carbon price due to its influence on the advances in emission reduction technology [27, 28].

Although the literature have shown that EPU does have a significant effect on carbon fundamentals, including the supply and demand of the permits, studies that focus on the EPU-carbon return nexus are scarce. On the other side, although the existing literature have discussed the impact of economic policy uncertainty on several financial markets, the results obtained 
from the linear models are incapable of capturing the dynamic characteristics of the financial market. This paper applies a MS-VAR model to shed new light on the time-varying influence by the news-based measures of economic policy uncertainty developed by Baker et al. [29]. on carbon market returns. A two-regime Markov-Switching process is introduced into the VAR model to examine the impact of EPU during different stages of the carbon market. This approach is attractive because carbon price exhibits dramatic breaks and distinct changes in regime. Such breaks and changes in regimes in the time series process can result from events such as permit allocation, permit expiration, significant changes in emission policies and so on. Thus, switches in model parameters and standard errors should be allowed to avoid spurious empirical results. Using a nonlinear VAR model can help describe the dynamic impact of economic policy uncertainty on carbon markets under different conditions. Furthermore, the Markov-Switching model can intuitively divide the sample interval, which facilitates the analysis and testing of the causes and effects of nonlinearity.

The reminder of the paper will be organized as follows. Section 2 details the methodology, Section 3 explains the data and empirical results, and Section 4 concludes with policy recommendations.

\section{Model and Variables}

\subsection{The MS-VAR Model}

For time series data which has nonlinear characteristics,

$$
P_{i j}=\operatorname{Pr}\left\{s_{t}=j \mid s_{t-1}=i\right\}, \sum_{j=1}^{M} p_{i j}=1 \quad \forall \mathrm{I}, \mathrm{j} \in\{1, \ldots, \mathrm{M}\}
$$

The transition probability of st traversing the irreducible zone state can be represented by a Markov transition matrix:

$$
P=\left[\begin{array}{ccc}
p_{11} & \cdots & p_{1 M} \\
\vdots & \ddots & \vdots \\
p_{1 M} & \cdots & p_{M M}
\end{array}\right]
$$

Depends on whether the mean process or the intercept term is dependent on the regime, the MSVAR model has the following two forms.

$$
y_{t}-\mu\left(s_{t}\right)=\beta_{1}\left(s_{t}\right)\left(y_{t-1}-\mu\left(s_{t-1}\right)\right)+\beta_{2}\left(s_{t}\right)\left(y_{t-2}-\mu\left(s_{t-2}\right)\right)+\cdots+\beta_{p}\left(s_{t}\right)\left(y_{t-p}-\mu\left(s_{t-p}\right)\right)+e_{t}
$$

Where $s t \in\{1,2 \ldots, M\} ; e_{t} \sim N I D\left(0, \sum\left(s_{t}\right)\right) ; \mu\left(s_{t}\right), \beta\left(s_{t}\right), \sum\left(s_{t}\right)$ are all dependent on the regime. The above formula means that the regime switching will cause an immediate change in the mean of the yt process, that is, the mean jump model (referred as MSM-VAR). Otherwise, if the mean has a smooth adjustment process after the regime switching, the regime-dependent intercept term is used to describe the yt process:

$$
y_{t}=\alpha\left(s_{t}\right)+\beta_{1}\left(s_{t}\right) y_{t-1}+\beta_{2}\left(s_{t}\right) y_{t-2}+\cdots+\beta_{p}\left(s_{t}\right) y_{t-p}+e_{t}
$$

Where $s_{t} \in\{1,2 \cdots, M\} ; e_{t} \sim N I D\left(0, \sum\left(s_{t}\right)\right)$. The above formula is also called an intercept-dependent model (referred as MSI-VAR).

Theoretically, all parameters in the model can be assumed as regime dependent, but too many parameters to be estimated will reduce the reliability of the results. In practice, depend on different research purposes, only some of the parameters are usually set to be regime dependent. With I indicates that the intercept is regime dependent, $\mathrm{M}$ indicates the mean is regime dependent, $\mathrm{H}$ indicates the error term heteroscedasticity, and $\mathrm{A}$ indicates the autoregressive parameter is regime dependent, the specifications of the MSVAR model under different assumptions of the variance is shown in Table 1. 
Table 1. Different Specifications of the MS-VAR models.

\begin{tabular}{lll}
\hline & MSM (time-variant $\boldsymbol{\mu}$ ) & MSI (time-variant $\boldsymbol{\alpha}$ ) \\
\hline constant $\Sigma$ & MSM-VAR & MSI-VAR \\
variant $\Sigma$ & MSMH-VAR & MSIH-VAR \\
\hline
\end{tabular}

Note: $\sum$ represents the variance of the error term, $\mu$ represents the mean, $\alpha$ represents the intercept term, and $\mathrm{H}$ represents heteroscedasticity.

\subsection{Variables}

\subsubsection{Carbon Price}

The closing price of Hubei Emission Allowance (HBEA) from China Hubei Emission Exchange is chosen to present the carbon price in China. The reason is that the total volume and amount of HBEA trading in Hubei Emission Exchange have been the largest among seven carbon emission trading pilots in China. Weekly return of the HBEA price is calculated as follows: $r t=\ln (P t)-\ln (P t-1)$, where $P t$ represents the closing price of HBEA on the last day of week t and $P t-1$ is the closing price of HBEA on the last day of week $t-1$. The data are collected from the website of the China Carbon Emissions Trading (http://k.tanjiaoyi.com/).

\subsubsection{Economic Policy Uncertainty}

Economic policy uncertainty is not directly observable and, therefore, must be constructed from observable variables. While, there exists no clear-cut consensus in terms of which approach to use in constructing measures of economic policy uncertainty, the news-based measures of uncertainty, as developed by Baker et al. [29], seem to have gained tremendous popularity in various applications in macroeconomics and finance [32]. This EPU measure encapsulates a wide range of policy uncertainty terms that appeared in the newspapers. For China, the South China Morning Post published in Hong Kong is used to collect the information. Articles on the newspaper is searched for the keywords such as 'uncertainty', 'economic/economy', 'policy', 'tax', 'regulation' and so on. The EPU index is downloaded from the economic policy uncertainty website (www.policy uncertainty.com/). Since only monthly data is available for China's EPU index, the Cubic-match last method is used to convert the monthly data to weekly data.

\subsubsection{Control Variables}

Besides economic policy uncertainty, there are other factors that may affect carbon price, including oil price, coal price, natural gas price and macroeconomic situations. These factors are also introduced into the model to ensure the reliability of the model. The definitions of the variables are shown in Table 2.

Table 2. Variable Definitions.

\begin{tabular}{ll}
\hline Variables & Definition \\
\hline EPU & Baker's EPU Index \\
$\mathrm{hb}$ & Closing price of Hubei Emission Allowance \\
oil & Closing price of fuel oil futures traded on Shanghai Futures Exchange \\
coal & Closing price of the thermal coal futures traded on Zhengzhou Commodity Exchange \\
$\operatorname{lng}$ & Ratio of the price of LNG to the price of thermal coal futures \\
ser & Industrial value added of Hubei Province \\
\hline
\end{tabular}

Note: Data of oil, coal, lng and ser are from the Wind Database.

\section{Empirical Results}

\subsection{Descriptive Statistics of the Variables}

The descriptive statistics of the variables are shown in Table 3.

Table 3. Descriptive Statistics of the Variables.

\begin{tabular}{llllll}
\hline Variable & Obs & Mean & Std.Dev. & Min & Max \\
\hline hb & 192 & -0.0027 & 0.0573 & -0.4331 & 0.3133 \\
EPU & 192 & 0.0037 & 0.1156 & -0.2942 & 0.3490 \\
oil & 192 & -0.0004 & 0.0460 & -0.1826 & 0.2494 \\
coal & 192 & 0.0006 & 0.0319 & -0.1364 & 0.1055 \\
lng & 192 & 0.0011 & 0.0454 & -0.1800 & 0.2234 \\
ser & 192 & -0.0023 & 0.0099 & -0.0600 & 0.0257 \\
\hline
\end{tabular}

\subsection{Empirical Results from the MSVAR Model}

The first step in establishing a MSVAR model is to specify the optimal lag order of the VAR part. According to the values of the log likelihood, AIC and SIC, the optimal VAR model is VAR(1). The second step is to specify the form of the MS part. By model comparison, the optimal specification for the MS part is $\operatorname{MSIH}(2)$ Therefore, in the following analysis, the $\operatorname{MSIH}(2)-\operatorname{VAR}(1)$ model is applied, i.e. there are two regimes with lag of first order and the intercept and variance are varying with different regimes.
The regression results are shown in Table 4.

As shown in Table 4, the standard deviation of regime 1 is larger than the standard deviation of regime 2, so regime 1 represents the period of high volatility on Hubei carbon market and regime 2 represents the period of low volatility. From the estimations of the coefficients, it can be seen that the impact of economic policy uncertainty on Hubei carbon price is significantly positive. As mention above, with higher economic policy uncertainty, the firms would be reluctant to invest in emission reduction technologies, resulting in higher emission and higher demand for emission permits, thus leading to higher carbon price.

Table 4. Empirical Results from MSVAR model.

\begin{tabular}{ll}
\hline & hb \\
\hline Const (Reg.1) & $-0.0090(-0.8868)$ \\
Const (Reg.2) & $0.0018(0.5838)$ \\
EPU & $0.0583^{* *}(2.2422)$ \\
oil & $0.0386(0.6750)$ \\
coal & $-0.2208^{*}(-1.9289)$ \\
lng & $-0.0432(-0.5628)$ \\
ser & $0.1846(0.5536)$ \\
SE (Reg.1) & 0.0839 \\
SE (Reg.2) & 0.0300 \\
\hline
\end{tabular}

Note: $\mathrm{t}$ statistics in the parentheses. 
As shown in Table 4, the standard deviation of regime 1 is larger than the standard deviation of regime 2, so regime 1 represents the period of high volatility on Hubei carbon market and regime 2 represents the period of low volatility. From the estimations of the coefficients, it can be seen that the impact of economic policy uncertainty on Hubei carbon price is significantly positive. As mention above, with higher economic policy uncertainty, the firms would be reluctant to invest in emission reduction technologies, resulting in higher emission and higher demand for emission permits, thus leading to higher carbon price.

Figure 1 shows the probabilities of two regimes on Hubei carbon market. As it shows, during the sample period, the probabilities of Hubei carbon market staying in regime 2 are much higher than the probabilities of it staying in regime 1. That means that the Hubei carbon market mostly stays in a low volatility state.
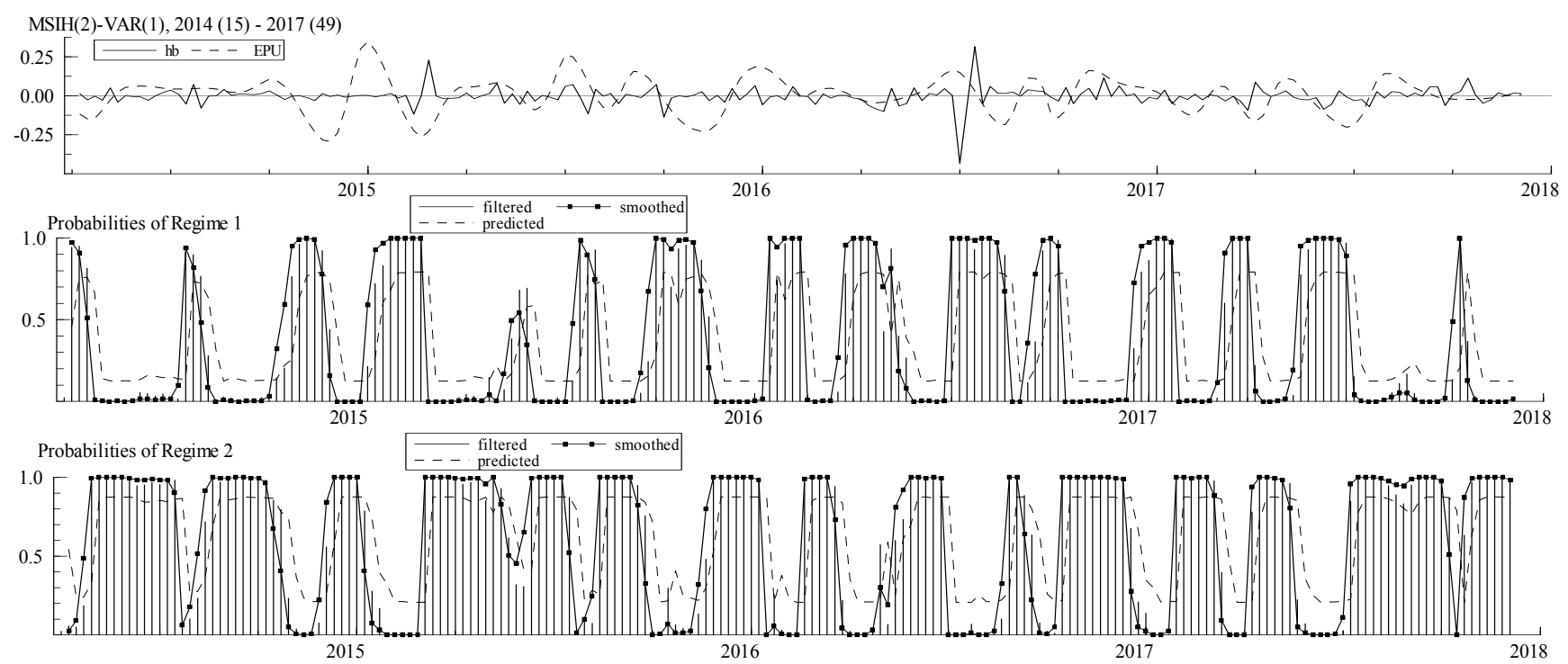

Figure 1. Probabilities of Two Regimes on Hubei Carbon Market.

Table 5. Regime Transition Probability Matrix.

\begin{tabular}{lll}
\hline hb & Regime 1 & Regime 2 \\
\hline Regime 1 & 0.7927 & 0.2073 \\
Regime 2 & 0.1232 & 0.8768 \\
\hline
\end{tabular}

Table 5 shows the estimated results of the regime transition probabilities. The probability of maintaining in regime 1 (high volatility period of Hubei carbon market) is 0.7927 , and the probability of maintaining $t$ in regime 2 (low volatility period of Hubei carbon market) is 0.8768 . The probability of transition from regime 1 to regime 2 (the transition of Hubei carbon market from high volatility to low volatility) is 0.2073 , and the probability of the transition from regime 2 to regime 1 (the transition of Hubei carbon market from low volatility to high volatility) is 0.1232 . Since the probability of regime 2 is greater than the probability of regime 1 , the model is mainly maintained in the state of low volatility. Moreover, the transition probabilities are far lower than the probabilities of maintaining in regime 1 or regime 2 , indicating that the model is relatively stable in regime 1 or regime 2.

Table 6. Estimated Duration of Each System.

\begin{tabular}{llll}
\hline hb & Number of Obvs. & Average Duration & Probability \\
\hline Regime 1 & 72.8 & 24.82 & 0.3728 \\
Regime 2 & 118.2 & 8.12 & 0.6272 \\
\hline
\end{tabular}

Table 6 shows the estimated results of the duration of each regime. It can be seen from that the average duration of regime 1 is 24.82 weeks, and the average duration of regime 2 is 8.12 weeks. The probability of the model staying in regime 1 is much lower than the probability of the model staying in regime 2, meaning that for a longer time in the sample period, the model stays in regime 2 .

\subsection{Impulse Response of Carbon Price to EPU in Different Regimes}

In order to further investigate the dynamic relationship between EPU and Hubei carbon price, and to compare the differences in different regimes, the impulse response function is applied and the results are shown in Figure 2. Consistent with the above results from the MS-VAR model, the impacts of EPU on carbon prices are positive during two regimes. However, the degree of the impacts differs in two regimes. In regime 1, one standard deviation in EPU causes increase in carbon price immediately and the impact reaches a maximum of 0.0013 one week later, then the carbon price slowly decline to reach a steady state in 20 weeks. In regime 2 , the impact reaches a maximum of 0.0032 within one week, nearly three times of the impact in regime 1 and the duration of the impact, which is 19 weeks, is similar with that in regime 1. 

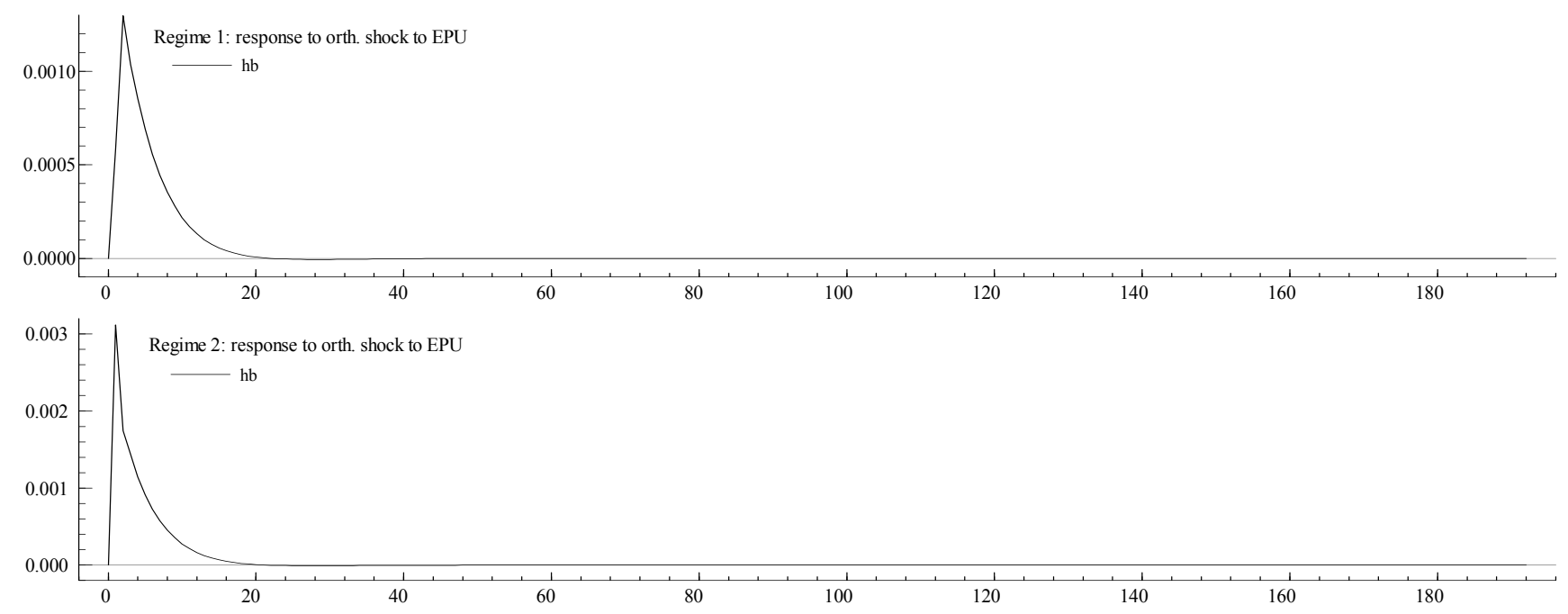

Figure 2. Impulse response of carbon price to EPU in different regimes.

The impulse response analysis shows that, compared with the high volatility period on carbon market, the impact of EPU on carbon price is higher in the low volatility period of carbon market. The reasons might be that the carbon market is primarily invested for risk diversification. Since the carbon market and traditional financial markets including stock market and bond market differ greatly in fundamental factors, their correlation is relatively low [33]. Therefore, many institutional investors regard the carbon market as the object of portfolio investment for risk diversification. As a matter of fact, according to the statistics, the main players on the European Union carbon market are not firms that subject to emission caps, but financial institutions [34]. When the carbon market is in a period of low volatility, more funds enter the market and use the market to diversify risks. Therefore, with higher economic policy uncertainties, the carbon market is affected to a larger extent. In contrast, when the carbon market is in a period of high volatility, the institutional investors will withdraw their funds from the carbon market. Therefore, with higher economic policy uncertainties, the carbon market is affected to a lower extent.

\section{Conclusion}

Previous literatures have identified the linkage between economic policy uncertainty and carbon price, but very limited work has been conducted to empirically test the impact of economic policy uncertainty on carbon price. Thus, this paper examines the impact of Chinese economic policy uncertainty on Hubei carbon price by using weekly data from April 2014 to December 2017. A MS-VAR model is applied to take into consideration of the structural breaks and regime transitions in carbon price. Empirical results from the MS-VAR model show that Chinese economic policy uncertainty has significantly positive impact on Hubei carbon price. The impulse response analysis shows that the impact of Chinese economic policy uncertainty on Hubei carbon price is larger during the low volatility period on carbon market than that during the high volatility period on carbon market.

The findings provide valuable implications for academics, policymakers as well as investors. The identified relationship between the EPU and carbon price implies that uncertainty in economic policy causes changes on carbon market; thus, in the study on the carbon market, the impact of economic policy uncertainty should be taken into consideration. The findings are also helpful for the investors in terms of managing their portfolio. It is suggested to carbon market investors that the economic policy uncertainty should be paid enough attention and the government and the economic policies should be closely monitored in a cautious manner.

\section{References}

[1] Brogaard, J., Detzel, A., 2015. The asset-pricing implications of government economic policy uncertainty [J]. Manage. Sci. $61,3-18$.

[2] Jones, P. M., Olson, E., 2013. The time-varying correlation between uncertainty, output, and inflation: evidence from a DCC-GARCH model [J]. Econ. Lett. 118,33-37.

[3] Caggiano, G., Castelnuovo, E., Figueres, J., 2017. Economic policy uncertainty and unemployment in the United States: a nonlinear approach [J]. Monetary Econ. 67, 78-92.

[4] Scheffel E M. Accounting for the political uncertainty factor [J]. Journal of Applied Econometrics, 2016, 31(6): 1048-1064.

[5] Aastveit K A, Natvik G J, Sola S. Economic Uncertainty and the Effectiveness of Monetary Policy [J]. SSRN Electronic Journal, 2013, 89(5): 447-489.

[6] Christou C, Gupta R, Hassapis C. Does economic policy uncertainty forecast real housing returns in a panel of OECD countries? A Bayesian approach [J]. The Quarterly Review of Economics and Finance, 2017, 65: 50-60.

[7] Wang Y, Zhang B, Diao X, et al. Commodity price changes and the predictability of economic policy uncertainty $[\mathrm{J}]$. Economics Letters, 2015, 127: 39-42. 
[8] Beckmann J, Czudaj R. Exchange rate expectations and economic policy uncertainty [J]. European Journal of Political Economy, 2017, 47: 148-162.

[9] Zhang G, Han J, Pan Z, et al. Economic policy uncertainty and capital structure choice: Evidence from China [J]. Economic Systems, 2015, 39(3): 439-457.

[10] Wang Y, Chen C R, Huang Y S. Economic policy uncertainty and corporate investment: Evidence from China [J]. Pacific-Basin Finance Journal, 2014, 26: 227-243.

[11] Li X M, Zhang B, Gao R. Economic policy uncertainty shocks and stock-bond correlations: Evidence from the US market [J]. Economics Letters, 2015, 132: 91-96.

[12] Li X M, Peng L. US economic policy uncertainty and co-movements between Chinese and US stock markets [J]. Economic Modelling, 2017, 61: 27-39.

[13] Liu L, Zhang T. Economic policy uncertainty and stock market volatility $[\mathrm{J}]$. Finance Research Letters, 2015, 15: 99-105.

[14] Sun X, Yao X, Wang J. Dynamic interaction between economic policy uncertainty and financial stress: A multi-scale correlation framework [J]. Finance Research Letters, 2017, 21: 214-221.

[15] Tsai I C. The source of global stock market risk: A viewpoint of economic policy uncertainty $[\mathrm{J}]$. Economic Modelling, 2017, 60: 122-131.

[16] Aatola P, Ollikainen M, Toppinen A. Price determination in the EU ETS market: Theory and econometric analysis with market fundamentals [J]. Energy Economics, 2013, 36: 380-395.

[17] Germà Bel, Joseph S. Emission abatement: Untangling the impacts of the EU ETS and the economic crisis [J]. Irea Working Papers, 2015, 49: 531-539.

[18] Christiansen A C, Arvanitakis A, Tangen K, et al. Price determinants in the EU emissions trading scheme $[\mathrm{J}]$. Climate Policy, 2005, 5(1): 16.

[19] Alberola E, Chevallier J, Beno?t Chèze. Emissions Compliances and Carbon Prices under the EU ETS: A Country Specific Analysis of Industrial Sectors [J]. Journal of Policy Modeling, 2009, 31(3): 446-462.

[20] Jaehnab F. The emissions trading paradox [J]. European Journal of Operational Research, 2010, 202(1): 248-254.

[21] Kautto N, Arasto A, Sijm J, et al. Interaction of the EU ETS and national climate policy instruments - Impact on biomass use [J]. Biomass \& Bioenergy, 2012, 38(none): 117-127.

[22] Benati L. Economic policy uncertainty and the great recession [J]. Journal of Applied Econometrics, 2013.

[23] Jones A T, Sackley W H. An uncertain suggestion for gold-pricing models: the effect of economic policy uncertainty on gold prices [J]. Journal of Economics and Finance, 2016, 40(2): $367-379$.

[24] Galinato G I, Yoder J K. An integrated tax - subsidy policy for carbon emission $[\mathrm{J}]$. Resource and Energy Economics, 2010, 32( 3): 310-326.

[25] Arellano C., Bai Y., Kehoe P. Financial Markets and Fluctuations in Uncertainty [R]. Federal Reserve Bank of Minneapolis Working Paper, 2010.

[26] Gilchrist S., Sim J. W., Zakrajsek E. Uncertainty, Financial Frictions, and Investment Dynamics [R]. Finance and Economics Discussion Series of Federal Reserve Board, 2014, No.2014-69.

[27] Gulen, H. and Ion, M. Policy Uncertainty and Corporate Investment [J]. Review of Financial Studies, 2016, 29( 3), pp. 523-564.

[28] Julio, B. and Yook, Y. Political Uncertainty and Corporate Investment Cycles [J]. The Journal of Finance, 2012, 67( 1), pp. $45-83$.

[29] Baker S. R., Bloom N., \& Davis S. J., Measuring Economic Policy Uncertainty [J]. The Quarterly Journal of Economics, Vol.131, 1 November 2016, Pages 1593-1636.

[30] Hamilton J. D., A New Approach to the Economic Analysis of Nonstationary Time Series and the Business Cycle [J]. Econometrica, Vol. 57, No. 2, Mar 1989, pp. 357-384.

[31] Krolzig H. M., Markov-Switching Vector Autoregressions [M]. Berlin: Springer, 1997.

[32] Redl C. Macroeconomic uncertainty in south africa [J]. South African Journal of Economics, 2018, 86(3): 361-380.

[33] Li H., \& An H., How Does the Coal Stock Market, Carbon Market and Coal Price Co-movement with Each other in China: A Co-movement Matrix Transmission Network Perspective [J]. Energy Procedia, Vol. 105, May 2017, Pages 3479-3484.

[34] Zhang Y., Liu Z., \& Yu X., The Diversification Benefits of Including Carbon Assets in Financial Portfolios [J]. Sustainability, Vol.9, March 2017, pages 437. 